MUÑOZ, Julián Andrés. "Expertos y política criminal en Colombia".

Polít. crim. Vol. 12, No 23 (Julio 2017), Art. 8, pp. 267-290.

[http://www.politicacriminal.cl/Vol_12/n_23/Vol12N23A8.pdf]

\title{
Expertos y política criminal en Colombia
}

\section{Experts and criminal policy in Colombia}

\author{
Julián Andrés Muñoz Tejada* \\ Profesor Facultad de Derecho y Ciencias Políticas, Universidad de Antioquia \\ julian.munozt@udea.edu.co
}

\section{Resumen}

Grupos de expertos son convocados a menudo por los gobiernos colombianos para que presenten diagnósticos y propuestas referidas a los problemas de violencia y criminalidad. Este artículo analiza el trabajo de algunos de esos grupos o comisiones y el impacto de sus recomendaciones en el diseño de la política criminal o, más concretamente, de la legislación penal producida en la segunda mitad del siglo veinte. El texto contiene algunas reflexiones sobre las condiciones de integración de ese tipo de comisiones, y los efectos que ellas producen en el reconocimiento de "los expertos". Es importante anticipar que la guerra es un elemento de contexto común en los grupos de expertos, en las recomendaciones que formularon y las normas penales que se analizaron en este artículo. De ahí las alusiones a las relaciones entre guerra y derecho penal a lo largo del escrito.

Palabras clave: Expertos, recomendaciones, política criminal.

\begin{abstract}
Expert commissions are often convened by Colombian governments to diagnose and submit proposals concerning the problems of violence and crime. This article analyzes the work of some of those groups or commissions and the impact of their recommendations in the design of criminal policy or more specifically of legislation produced in the second half of the twentieth century. The text contains some reflections on the conditions of integration of such commissions, and the effects they produce in the recognition of "experts". It is important to anticipate that war is a common element of context in these expert groups, on their recommendations and on criminal laws analyzed in this article. This explains the references to the relations between war and criminal law in the paper.
\end{abstract}

\footnotetext{
* Este artículo corresponde al informe final de la investigación. "Contribuciones e impactos de las comisiones de expertos en el diseño de la política criminal en Colombia” financiada por el Comité para el Desarrollo de la Investigación -CODI- de la Universidad de Antioquia. Una primera versión de este trabajo se presentó en el VIII Congreso Latinoamericano de Ciencia Política, organizado por la Asociación Latinoamericana de Ciencia Política (ALACIP) y llevado a cabo en la Pontificia Universidad Católica del Perú, Lima, 22 al 24 de julio de 2015. El autor agradece la colaboración de quienes integraron hasta el final el equipo de investigación: profesor William Pérez Toro, co-investigador, el estudiante de la Maestría en Ciencia Política del Instituto de Estudios Políticos (hoy magíster en Ciencia Política) Ricardo Cruz Baena; la estudiante del pregrado en Ciencia Política (hoy politóloga y magíster en Gobierno y Políticas Públicas) Diana Paola Rojas Bermeo y al estudiante del pregrado en Ciencia Política (hoy politólogo) Luis Carlos Arbeláez Villegas.
} 
MUÑOZ, Julián Andrés. "Expertos y política criminal en Colombia".

Key words: Experts, recommendations, criminal policy.

En última instancia, mientras más autoridad tiene el experto, menos competencia posee, hasta que su fondo se agota (...).

Michel de Certeau

\section{Introducción.}

En el campo de los estudios sobre violencia y criminalidad en Colombia, es común encontrar extensos informes producidos por grupos de expertos que, en contextos y períodos diversos, se han ocupado de diagnosticar la situación y de recomendar medidas institucionales referidas directamente a la penalidad. En los casos más reconocidos, los expertos que producen aquellos informes se agrupan en "comisiones" convocadas por el gobierno nacional (para la reforma ${ }^{1}$, para el análisis de la política criminal ${ }^{2}$ o para el estudio de la violencia ${ }^{3}$ ). No obstante, se encuentran también grupos de expertos cuya integración no se define por un acto formal de convocatoria, sino por una fuerte afinidad teórica y metodológica; expertos que no actúan oficialmente como una "comisión", pero que tienen la suficiente cercanía con los gobiernos como para que sus perspectivas y recomendaciones sean escuchadas ${ }^{4}$.

Pero ¿cuál ha sido la influencia del trabajo de esos expertos en el diseño de las políticas? Ese es el interrogante genérico que inspiró la investigación de la cual se deriva el texto que ahora se presenta. El objetivo de trabajo, por lo tanto, consistió en saber si -y cómo- las propuestas de los expertos han impactado la política criminal o, más concretamente, cómo han moldeado la legislación penal. No se trataba -ni se trata en este texto- de medir el impacto que sobre la criminalidad han tenido las conclusiones y recomendaciones de los

\footnotetext{
${ }^{1}$ Las "comisiones redactoras" de códigos penales tienen una larga historia: la ley 23 de 1886, por ejemplo, creó una comisión para preparar un proyecto de código penal (la integraron los consejeros de estado Demetrio Porras, Clodomiro Tejada, Luis Carlos Rico y Juan Pablo Restrepo); la ley 81 de 1923 designó una comisión de tres especialistas para el estudio de las modificaciones al proyecto de código penal presentado por José Vicente Concha (integrada por los juristas José Antonio Montalvo, Luis Rueda Concha, Parmenio Cárdenas, Rafael Escallón, Valerio Botero y Miguel Vargas Vásquez). Igualmente, la ley 20 de 1933 creó la comisión preparatoria del Código Penal Colombiano de 1936. Más adelante se integraría la comisión redactora del código de 1980, a la cual se aludirá más adelante.

${ }^{2}$ Por ejemplo: COMISIÓN ASESORA PARA EL DISEÑO DE LA POLÍTICA CRIMINAL DEL ESTADO COLOMBIANO, creada en 2011, produjo los informes Observaciones a la iniciativa sobre la imposición de cadena perpetua a ciertos delitos realizados contra menores (2011), y Diagnóstico y propuesta de lineamientos de política criminal para el Estado colombiano (2012). La Comisión Asesora para la Política de Drogas en Colombia, dio a conocer en 2013 su informe Lineamientos para una política pública frente al consumo de drogas.

${ }^{3}$ Además de comisiones de estudio sobre la violencia, hay casos "de menor alcance" como las comisiones técnicas transitorias de actualización jurídica y fortalecimiento institucional, de reducción de oferta de drogas ilícitas y de reducción de la demanda de drogas, creadas durante el período de gobierno 2002-20010. Véase: JARAMILLO, Jefferson, "Expertos y comisiones de estudio sobre la violencia en Colombia", Estudios Políticos, $\mathrm{n}^{\circ} 39$ (2011), pp. 231-258.

${ }^{4}$ Especialmente desde los años noventa, como se verá, el caso típico es el de los expertos "convocados" por los enfoques económicos del crimen.
} 
Polít. crim. Vol. 12, № 23 (Julio 2017), Art. 8, pp. 267-290.

[http://www.politicacriminal.cl/Vol_12/n_23/Vol12N23A8.pdf]

expertos; tampoco de ponderar el mayor o menor acierto de sus diagnósticos en relación con "las verdaderas causas" del fenómeno. En el medio existen ya rigurosos estados del arte y análisis críticos al respecto ${ }^{5}$.

Aquí se indaga, en cambio, por un momento previo al de la "puesta en práctica" de las recomendaciones de los expertos: el momento del diseño de la reacción penal. Es un momento poco estudiado y que puede resultar importante para comprender la decisión político criminal en Colombia, el lugar de los expertos, la relación entre producción de conocimiento y política penal, los factores que hacen un conocimiento políticamente relevante o irrelevante en ese campo y, finalmente, las dificultades que enfrenta la democracia colombiana a la hora de responder al problema social de la criminalidad a través del castigo penal.

Con ese objetivo, el trabajo examinó la legislación penal producida en tres períodos: 19651987, 1988-1995 y 1996-2000, y el trabajo de las comisiones de expertos que, en cada momento, pudieron haber incidido en las decisiones de política criminal correspondientes ${ }^{6}$. Conforme al diseño metodológico de la investigación, y de acuerdo con las pruebas preliminares de análisis, esa periodización permite captar con menos perturbaciones - o con menos sesgos- el impacto de los dictámenes de las comisiones y grupos de expertos seleccionados para el estudio.

Además, pese a la secuencialidad de esos lapsos de tiempo, la normatividad y los informes expertos que se remiten a cada período tienen contextos sociales y políticos con rasgos suficientemente diferenciables, lo cual otorga mayor solidez a las generalizaciones que pueden encontrarse en la relación entre expertos y decisiones político criminales. Finalmente, la progresión temporal indicada facilitó una metodológica abductiva ${ }^{7}$ proyectada para el desarrollo de la investigación, es decir, una estrategia que permitió rebatir o ajustar consciente y progresivamente las hipótesis o "conjeturas" iniciales, con base en el agregado de información sobre cada período de producción legislativa y de publicación de informes expertos.

Este artículo está dividido en tres apartados. En el primero se alude rápidamente al lugar social de ciertos depositarios de conocimiento y al "experto" como el típico conocedor contemporáneo que media entre el saber especializado y el mundo de la política. En el segundo apartado se exponen los rasgos más comunes de los grupos de expertos estudiados

\footnotetext{
${ }^{5}$ Véase: CUARTAS, Deiman, Los nuevos estudios sobre las causas de la violencia en Colombia: giro epistemológico e implicaciones políticas e institucionales, 1990-2010, Informe de Investigación, 2015 (inédito); CUARTAS, Deiman; VALENCIA, Germán, "Exclusión económica y violencia en Colombia, 19902008: Una revisión de la literatura", Perfil de Coyuntura Económica, nº 14 (2009), pp. 113 - 134.

${ }^{6}$ La investigación se valió de un intenso trabajo documental y de entrevistas a personas que participaron o que conocen de cerca el trabajo y las lógicas de funcionamiento de las comisiones de expertos. Aquí se incluyen entrevistas realizadas a expertos miembros de la Comisión de Estudios sobre la Violencia en Colombia o "violentólogos" (2); de la Comisión Asesora de Política Criminal (1) y de la más reciente Comisión sobre el Conflicto y sus Víctimas (1). Un experto de reconocido en el campo de la seguridad y la violencia, también hizo parte de "la muestra".

${ }^{7}$ SWEDBERT, Richard, The art of social theory, Princeton: Princeton University Press, 2014, pp. 169-187; TIMMERMANS, Stefan; TAVORY, Iddo, "Theory construction in qualitative research: from grounded theory to abductive analysis", Sociological Theory, no 30 (2002), pp. 167-186.
} 
MUÑOZ, Julián Andrés. "Expertos y política criminal en Colombia".

en la investigación. En el tercer apartado se presenta el análisis de la legislación penal colombiana en los períodos estudiados, con un énfasis especial en la vía prioritaria de producción de derecho penal en Colombia durante la época: el estado de excepción. Es una muestra de que en el contexto de un conflicto armado de larga duración como el colombiano, las relaciones entre guerra y derecho penal son ineludibles. También en este tercer apartado, como en las conclusiones finales, se discute el grado de la incidencia de las recomendaciones de las comisiones de expertos que fueron objeto de estudio, en la legislación penal.

\section{Intelectuales y expertos.}

Los vínculos entre conocimiento y poder político han sido explorados en las figuras del "intelectual" y del "experto" 8 . El intelectual ha sido concebido de forma diversa conforme a su profunda y extensa relación con el saber y a su capacidad de decir. Así, el intelectual universal sería aquel que tiene la posibilidad de acceder a "todo" el conocimiento disponible en un momento determinado. Se corresponde con la idea de los "sabios" del Medievo o del mundo antiguo (Aristóteles o Leonardo Da Vinci, ilustran esa capacidad omnipotente en relación con el saber). El intelectual concreto, en cambio, sería producto de la modernidad y de la especialización del conocimiento. Dadas las especialidades y subespecialidades en las cuales se atomiza el conocimiento, el intelectual concreto -a diferencia del universal- no tendría ya cómo acceder a la totalidad del saber disponible. Por otra parte, el intelectual orgánico (gramsciano) sería el encargado de mantener y perfeccionar el orden social con sus conocimientos. Su rol fundamental será legitimar el orden político9. Finalmente el intelectual comprometido, tal como lo concibe la teoría crítica, asumiría la idea marxista de que el científico social tiene el deber no sólo de explicar y criticar, sino también de comprometerse con la práctica política orientada al cambio de las estructuras sociales ${ }^{10}$.

De otra parte, el "experto" -que interesa en este trabajo- es aquel portador de un conocimiento especializado que frecuentemente es consultado $-\mathrm{O}$ enganchado- por quienes ejercen poder político. Lo que hace importantes a los expertos no es que sean "los mejores" en sus respectivos campos sino, como sostiene Michel de Certeau, que sean capaces de mediar, de traducir el mundo del conocimiento científico y hacerlo útil en el de la política:

"Es verdad que el experto prolifera en esta sociedad, al punto de volverse la figura generalizada, distendida entre la exigencia de una creciente especialización y la de una comunicación tanto más necesaria. Borra (y en cierta manera reemplaza) al filósofo, al ayer especialista de lo universal. Pero su éxito no es realmente espectacular. La ley

\footnotetext{
${ }^{8}$ Conviene recordar que, a partir de sus indagaciones sobre la prisión, la psiquiatría y las ciencias sociales, Michel Foucault sugiere que "el ejercicio del poder crea perpetuamente saber e inversamente el saber conlleva efectos de poder”. FOUCAULT, Michel, Microfísica del poder. Madrid: Ediciones de la Piqueta, 1992, p. 109.

9 URREGO, Miguel, Intelectuales, Estado y Nación en Colombia: de la guerra de los mil días a la Constitución de 1991, Bogotá: Siglo del Hombre, 2002, p. 12.

${ }^{10}$ En esa imbricación entre militancia política y conocimiento surgiría la ciencia social comprometida; una suerte de compromiso del conocimiento científico con cambios sociales y políticos. En el contexto de la guerra fría, esa ciencia sería vista como subversiva. SANDOVAL, Emiro, Sistema penal y criminología crítica, Bogotá: Temis, 1985, p. 92.
} 
Polít. crim. Vol. 12, № 23 (Julio 2017), Art. 8, pp. 267-290.

[http://www.politicacriminal.cl/Vol_12/n_23/Vol12N23A8.pdf]

productivista de un requerimiento (condición de una eficacia) y la ley social de una circulación (forma de intercambio) se contradicen en él. En efecto, cada vez más, todo especialista debe ser también un experto, es decir, el intérprete y el traductor de su competencia en otro campo. Esto se manifiesta en el interior mismo de los laboratorios: en cuanto se trata de pronunciarse sobre objetivos, promociones o financiamientos, los expertos intervienen "en nombre" - pero fuera- de su experiencia particular. ¿Cómo llegan a pasar de su técnica -una lengua dominada y reguladora- a la lengua, más común, de otra condición? Mediante una curiosa operación que "convierte" la capacidad en autoridad. En última instancia, mientras más autoridad tiene el experto, menos competencia posee, hasta que su fondo se agota, como la energía necesaria para el lanzamiento de un móvil. Durante el tiempo de esta conversión, no se encuentra sin competencia (necesita una, o hacer creer que tiene una), pero abandona la que posee a medida que su autoridad se extiende más lejos, exorbitada por la demanda social o por las responsabilidades políticas ${ }^{11}$.

Josep Colomer, afirma igualmente que debido a la mayor complejidad de los asuntos de la política contemporánea, sólo los especialistas en ciertas materias están llamados a desentrañar ese mundo complejo que los no expertos están en incapacidad de comprender. Aunque muchas veces sea el azar -y no la experticia- la que hace al experto ${ }^{12}$.

Los expertos, cuya incidencia o vinculación directa en las estructuras de gobierno dan sentido a la "tecnocracia", han portado y ofrecido conocimientos provenientes principalmente de la economía. No es casual que en América Latina la irrupción de la tecnocracia coincida con el arribo del pensamiento neoliberal; o que las recomendaciones de la Escuela de Chicago (de los expertos "Chicago Boys") moldearan de manera tan determinante las políticas económicas de países en "vías de desarrollo"13.

Sin embargo, la racionalidad tecnocrática no solo ha permeado las grandes decisiones fiscales, financiaras, tributarias y afines, sino que ella ha constituido en realidad un "nuevo sentido común que informa las políticas públicas nacionales" 14 . No es extraño por eso que el dominio de esos específicos expertos se encuentra en muchos otros campos.

"El proyecto económico neoliberal (...) demandó la supremacía del economista quien por su formación, la presencia de las matemáticas en el currículum, aparece con el aura del científico riguroso y, dada la coyuntura histórica de la supuesta muerte de las ideologías y la desaparición de los intelectuales, se constituyen en fuente de legitimación. Explica Marco Palacios que «debido a su formación, los economistas se vuelven indispensables para los políticos que dirigen el Estado, para los grupos de poder económico, y en los procesos de formación de leyes en el Congreso.»"15.

\footnotetext{
${ }^{11}$ DE CERTAU, Michel, La invención de lo cotidiano 1, artes de hacer, PESCADOR, Alejandro (Trad.), México: Universidad Iberoamericana, 2007, p. 11.

${ }^{12}$ COLOMER, Josep, El gobierno mundial de los expertos, Barcelona: Anagrama, 2015, p. 55.

13 Adicionalmente, como señala Klein, habría en general una correspondencia entre liberalización de los mercados y crisis políticas. KLEIN, Naomi, The shock doctrine, en: www.youtube.com. Recuperado el 15 de Marzo de 2013, de The Shock Doctrine: https://www.youtube.com/watch?v=Qm4_vdGkD7o, 2013.

14 BOUZAS, Roberto; FFRENCH-DAVIS, Ricardo, "Globalización y políticas nacionales: ¿cerrando el círculo?”, Revista de Desarrollo Económico, vol. 45, n 179 (2005), pp. 323-348, p. 336.

15 URREGO, Miguel, Intelectuales, Estado y Nación en Colombia: de la guerra de los mil días a la Constitución de 1991, Bogotá: Siglo del Hombre, 2002, pp. 207-208.
} 
MUÑOZ, Julián Andrés. "Expertos y política criminal en Colombia".

\section{Los grupos de expertos.}

Como se ha dicho, este texto se fija específicamente en el impacto que los estudios de diversos grupos de expertos pueden haber producido en una política, la política criminal. En este apartado se apuntan algunos rasgos característicos de esos grupos. Sin embargo, previamente conviene aclarar el uso que se hace aquí de los conceptos de política criminal y política penal. Entre otras cosas, porque esa distinción fue uno de los primeros desafíos de la investigación.

Desde la introducción de este texto, como se habrá notado, se otorga un significado similar a las expresiones política criminal y política penal; o más exactamente, el significado del primer concepto ha sido reducido al del segundo. La situación se explica por lo siguiente: La investigación de la cual forma parte este informe, asumió en un principio que esas expresiones aludían a fenómenos diferenciables, tal como convencionalmente lo hacen $-\mathrm{O}$ se esfuerzan por hacerlo- penalistas y criminólogos. Pero a medida que avanzaba la observación y el análisis del problema, se hizo prácticamente imposible saber qué era lo propio de la política criminal y qué lo era de otras políticas.

En efecto, una noción tan amplia de política criminal como la que hoy prevalece (en el discurso de políticos y gobernantes, en las decisiones de altos tribunales y en el lenguaje de muchos académicos), hace imposible localizar con precisión un campo en el cual se localicen con exclusividad las respuestas institucionales al delito. Es elocuente la definición de política criminal hecha por la Corte Constitucional colombiana en $2001^{16}$, adoptada por a su vez por la Comisión Asesora de Política Criminal creada por gobierno colombiano en 2011 e integrada por "una conjunción de expertos y expertas quienes desde diferentes ópticas expusieron sus conocimientos teóricos y prácticos sobre las condiciones estructurales y micro-sociales de cada uno de los campos abordados" $" 17$ :

Es [la política criminal] el conjunto de respuestas que un Estado estima necesario adoptar para hacerle frente a conductas consideradas reprochables o causantes de perjuicio social con el fin de garantizar la protección de los intereses esenciales del Estado y de los derechos de los residentes en el territorio bajo su jurisdicción. Dicho conjunto de respuestas puede ser de la más variada índole. Puede ser social, como cuando se promueve que los vecinos de un mismo barrio se hagan responsables de alertar a las autoridades acerca de la presencia de sucesos extraños que puedan estar asociados a la comisión de un delito. También puede ser jurídica, como cuando se reforman las normas penales. Además puede ser económica, como cuando se crean incentivos para estimular un determinado comportamiento o desincentivos para incrementarles los costos a quienes realicen conductas reprochables. Igualmente puede ser cultural, como cuando se adoptan campañas publicitarias por los medios masivos de comunicación para generar conciencia sobre las bondades o consecuencias nocivas de un determinado comportamiento que causa grave perjuicio social. Adicionalmente pueden ser administrativas, como cuando se aumentan las medidas de seguridad carcelaria. Inclusive pueden ser tecnológicas, como cuando se decide emplear de

\footnotetext{
16 Corte Constitucional Colombiana, Sentencia C-646, 2001. En: http://www.corteconstitucional.gov.co/relatoria/2001/C-646-01.htm, [visitado 22.08.2016].

${ }^{17}$ CORREA, Ruth (Ministra de Justicia y del Derecho), "Agradecimientos". En: COMISIÓN ASESORA DE POLÍTICA CRIMINAL, Informe Final, cit. nota $\mathrm{n}^{\mathrm{o}} 2$, p. 7.
} 
Polít. crim. Vol. 12, № 23 (Julio 2017), Art. 8, pp. 267-290.

[http://www.politicacriminal.cl/Vol_12/n_23/Vol12N23A8.pdf]

manera sistemática un nuevo descubrimiento científico para obtener la prueba de un hecho constitutivo de una conducta típica ${ }^{18}$.

Un concepto de política criminal que la defina así, en términos multiagenciales y multinivel, puede ser políticamente plausible y hasta progresista, pero evidentemente no es operativa. O por lo menos no lo es para el análisis que aquí se pretende. Es imposible establecer deslindes si se asume que cada ámbito de intervención (social, cultural, educativo, de infraestructura urbana, policial, comunitario, militar, etc.), cada nivel territorial (nacional, regional y local), y prácticamente cualquier institución pública y muy diversos agentes privados, hacen o configuran, conforman o integran, aplican u operan la política criminal. Por eso, cuando en este texto se alude al nexo entre "política criminal" y "expertos", debe entenderse que se trata de una relación entre expertos y política penal.

Así entonces, del vasto conjunto de medios que se dirigen a definir, delimitar, perseguir, controlar, neutralizar o reducir la criminalidad, la investigación de la cual surge este texto examinó el instrumento jurídico penal, es decir, esa manifestación de poder político que se hace norma penal a través de leyes expedidas por el Congreso o decretos con fuerza de ley dictados por el Presidente. Concretamente se tuvo en cuenta la legislación expedida hasta la promulgación del Código Penal Colombiano de 2000 (ley 599) ${ }^{19}$.

De otra parte, como se ha dicho, se examinaron y contrastaron las conclusiones y propuestas presentadas por tres grupos de expertos que, en diferentes períodos, convergieron de diversas maneras (por convocatoria formal o por afinidad temática) en la tarea de diagnosticar la situación de violencia y criminalidad y de proponer reformas en el campo de la penalidad. Los grupos de expertos examinados, son los siguientes:

a) Comisión Nacional Investigadora de las causas y situaciones presentes de violencia en el territorio nacional ${ }^{20}$. Esta comisión se mantuvo activa entre mayo de 1958 y enero de 1959, y fue convocada por la Junta Militar que ejerció el gobierno de Colombia entre mayo de 1957 y agosto de 1958, es decir, durante la transición de la dictadura del General Gustavo Rojas (1953-1957) hacia el pacto consocionalista del Frente Nacional (1958 y $1974)^{21}$. Aunque no se conoció un informe final de la comisión, parte "de sus hallazgos"22

\footnotetext{
${ }^{18}$ COMISIÓN ASESORA DE POLÍTICA CRIMINAL, Informe final, cit. nota ${ }^{\circ}$ 2, p, 12

${ }^{19}$ Una pesquisa de mayor alcance, puede consultar los informes del Consejo Superior de Política Criminal y del Observatorio de Política Criminal: http://www.politicacriminal.gov.co/Inicio/Consejo-Superior-dePol\%C3\%ADtica-Criminal. [visitado el 15.05.2016].

${ }^{20}$ Mediante Decreto Legislativo se ordenó integrar la comisión con ocho miembros "nombrados por el Gobierno y en la cual tengan participación representativos de los partidos políticos, las fuerzas armadas y la iglesia" (artículo 1). El encargo de la comisión era este: a) Un “estudio directo en aquellos Departamentos o regiones del país más afectado por el desorden y la delincuencia, con el propósito de localizar el conjunto de móviles determinantes de esos fenómenos y de su perduración". b) Presentar informes al Gobierno "sobre el resultado de su misión", y hacer "sugerencias o recomendaciones destinadas a solucionar metódicamente las situaciones analizadas"; c) "Aconsejar las medidas tendientes a la rehabilitación económica y social de las zonas objeto del estudio (...) y al apoyo que deba prestarse a las víctimas de la violencia o a sus familiares" (artículo 2). Decreto Legislativo 165 de 1958. Diario Oficial. No. 29700, Año XCV, 28 de junio de 1958, p. 2

21 Es decir, la transición de una dictadura hacia una democracia "de bajísima intensidad" (GARCÍA, Mauricio, "Estado, derecho y crisis en Colombia", Estudios Políticos, no 17 (2000), pp. 11-44), o hacia un régimen "de bloqueo o veto de las élites a la nación" (URIBE, Mauricio, La nación vetada: Estado,
} 
MUÑOZ, Julián Andrés. "Expertos y política criminal en Colombia".

aparecieron en el libro La violencia en Colombia publicado en 1962. Refiriéndose a esta publicación, Jefferson Jaramillo afirma que la "radiografía regional de las secuelas del desangre que la Comisión logró parcialmente sería luego profundizada radicalmente por un libro que pronto devendría en la memoria emblemática de la época" ${ }^{\text {23 }}$.

En materia de política criminal, aquel libro contiene propuestas referidas a la necesidad de limitar los efectos y el uso recurrente de la legislación expedida al amparo del estado de sitio. De hecho, allí se advirtió desde entonces una "situación paradojal" que se haría recurrente en el orden normativo colombiano: "se levanta el estado de sitio, pero se consagra el régimen penal de época de guerra interna" ${ }^{24}$. La subordinación del legislativo al Gobierno era un aspecto crítico del régimen, según los expertos ${ }^{25}$.

b) Comisión de Estudios sobre la violencia en Colombia. Esta Comisión fue convocada en enero de 1987 por el presidente Virgilio Barco $^{26}$, en un momento en el cual violencia del narcotráfico alcanzaba niveles inéditos en el país, se hacía notorio el poder expansivo del paramilitarismo "de primera generación",27 y se encontraban en crisis los pactos que el gobierno había celebrado tres años atrás con algunos grupos guerrilleros ${ }^{28}$. Después de "cuatro escasos meses de discusión interna" "29, el informe final de la comisión sería pulicado bajo el título Colombia: violencia y democracia.

desarrollo y guerra civil en Colombia, Bogotá: Universidad Externado de Colombia, 2013). Alberto Lleras, presidente de la república entre 1958 y 1962 y firmante de los pactos de Benidorm (1956) y Sitges (1957) que dieron lugar al Frente Nacional, entendía este régimen como "la cura inmediata" a la violencia desatada desde finales de los años cuarenta. Esa violencia, sugería Lleras, aparecía y crecía cuando cualquiera de los partidos trataba de excluir al otro del manejo de la cosa pública (Véase: ZALAMEA, Alberto, Las jornadas de mayo, Bogotá: Antares, 1957, p. 57).

22 DE ZUBIRÍA, Andrés; BECERRA, Gabriel, "Proceso de paz y propuestas de cambio en el sistema político colombiano", Criterio Jurídico Garantista, no 13 (2015), pp. 90-107.

23 JARAMILLO, Jefferson, "El libro La Violencia en Colombia (1962-1964). Radiografía emblemática de una época tristemente célebre", Revista Colombiana de Sociología, vol. 35, $\mathrm{n}^{\circ} 2$ (2012), p, 35. Sobre significado de aquel libro en la génesis de la sociología política o en la institucionalización de los estudios políticos en Colombia, véase: LEAL, Francisco, "La profesionalización de los estudios políticos en Colombia", Análisis Político, no 3 (1988), pp. 61-80, p. 66.

${ }^{24}$ FALS, Orlando et al., La violencia en Colombia, Vol. I. Bogotá: Santillana, 2010, pp. 427-428.

${ }^{25}$ FALS, La violencia en Colombia, cit. nota n ${ }^{\circ} 24$, pp. 502-503.

26 "El interés del gobierno -según señaló el ministro- era consultar a académicos experimentados en la investigación de la violencia su opinión acerca de las perspectivas de este fenómeno, y al mismo tiempo sobre el tipo de medidas que podrían contribuir a frenar su inquietante avance". COMISIÓN DE ESTUDIOS SOBRE LA VIOLENCIA, Colombia: Violencia y Democracia. $1^{\text {a }}$ Edición, Bogotá: Universidad Nacional de Colombia, 1987, p. 9.

${ }^{27}$ La literatura especializada suele referirse a los grupos paramilitares de primera generación como aquellos "nacidos como reacción a la presencia de los grupos guerrilleros y con un fuerte carácter de autodefensas armadas locales - tal como ocurrió en el Magdalena Medio-". COMISIÓN NACIONAL DE REPARACIÓN Y RECONCILIACIÓN. Disidentes, rearmados y emergentes: ¿bandas criminales o tercera generación?, p. 45, 2007, en: http://repository.oim.org.co/bitstream/20.500.11788/73/1/COLOIM\%200190.pdf, [visitado 22.08.2016].

${ }^{28}$ Dos años después de la presentación del informe, el presidente Barco lanzaría su propia "iniciativa para la paz" que derivaría finalmente en la desmovilización del grupo guerrillero M-19 (y más adelante, en la convocatoria de la Asamblea Nacional Constituyente de 1991).

${ }^{29}$ COMISIÓN DE ESTUDIOS SOBRE LA VIOLENCIA, Colombia: Violencia y Democracia. $1^{\mathrm{a}}$ edición. Bogotá: Universidad Nacional de Colombia, 1987, p. 10. En adelante se citará preferiblemente la siguiente 
Polít. crim. Vol. 12, № 23 (Julio 2017), Art. 8, pp. 267-290.

[http://www.politicacriminal.cl/Vol_12/n_23/Vol12N23A8.pdf]

Las explicaciones de la violencia y del crimen, así como las recomendaciones formuladas por los comisionados, estuvieron asociadas a causas objetivas de tipo estructural. En materia de política penal, el informe contenía recomendaciones sobre el fortalecimiento de la investigación criminal para hacer frente a la violencia organizada, y sobre la criminalización de conductas para intervenir otros problemas que la comisión consideraba críticos (como la extensión de la circunstancia de agravación del homicidio a las uniones maritales de hecho, para responder la violencia intrafamiliar) ${ }^{30}$.

c) Economistas expertos en la cuestión criminal. Por lo menos desde los primeros años de la década del noventa, algunos expertos en "economía del crimen" se ocuparon de rebatir las explicaciones precedentes sobre la violencia y la criminalidad en Colombia ${ }^{31}$. Se esforzaron especialmente en desacreditar la perspectiva de las "causas objetivas" y en proponer explicaciones basadas en el carácter racional del comportamiento violento y delincuencial $^{32}$. Sus recomendaciones en política penal se refirieron al fortalecimiento del aparato de administración de justicia, a la eficiencia del sistema penal y, en general, a la celeridad y efectividad de la pena como desincentivos del crimen.

Las características más destacadas -y coincidentes- de los grupos de expertos y de su relación con los gobiernos que los convocan o consultan, pueden ser descritas de acuerdo con las versiones de las fuentes directamente implicadas en esas tareas y conforme al análisis de las fuentes documentales referidas a la conformación y funcionamiento de las comisiones. Las siguientes son algunas de esas características:

\subsection{Justificación de las comisiones.}

La convocatoria de comisiones de expertos que abordan en algún momento la cuestión criminal, se suele fundar en finalidades como las siguientes: el trabajo de los expertos y la interdisciplinariedad lograrían introducir una perspectiva integral en la política criminal; la presencia de conocedores del tema "sobre el terreno" aportaría fortaleza empírica a las reformas legales; y el carácter experto o la especialidad de los convocados permitiría recuperar el verdadero sentido de última ratio que habría de tener el derecho penal.

edición: SÁNCHEZ, Gonzalo, Colombia: violencia y democracia. Medellín (Colombia): La Carreta editoresIEPRI, 2009.

${ }^{30}$ SÁNCHEZ, Colombia, cit. nota no 29, p. 143.

${ }^{31}$ Esa perspectiva tendría un importante desarrollo a partir de los trabajos de Gary Becker (1968) y de Isaac Ehrlich (1973). En su aplicación a la cuestión criminal, ella fue acogida con entusiasmo una vez Becker obtuviera el premio Nobel en 1992. Algunos de sus más conocidos difusores en Colombia (véanse: MONTENEGRO, Armando; POSADA, Carlos, "Criminalidad en Colombia", Coyuntura Económica, no 1(1995), pp. 81-100; CÁRDENAS, Mauricio; STEINER, Roberto (Compiladores), Corrupción, crimen y justicia: una perspectiva económica, Bogotá: TM Editores, 1998) ocuparían años después altos cargos en entidades gubernamentales colombianas o se vincularían a instituciones internacionales (Ministerio de Hacienda, Departamento Nacional de Planeación, Banco de la República, Ecopetrol, BID, FMI, CEPAL). Sobre el enfoque, véanse también: RUBIO, Mauricio, Crimen e impunidad. Precisiones sobre la violencia, Bogotá: CEDE (Uniandes) - Tercer Mundo, 1999; DEAS, Malcolm; GAITÁN, Fernando, Dos ensayos especulativos sobre la violencia en Colombia, Bogotá: FONADE - DNP, 1995; MARTÍNEZ, Astrid (Comp.), Violencia y crimen. Ensayos en memoria de Fernando Gaitán Daza, Bogotá: Universidad Externado de Colombia, 2006.

${ }^{32}$ Se destacan los trabajos de: RUBIO, Crimen e impunidad, cit. nota n ${ }^{\circ}$ 31; DEAS/GAITÁN, Dos ensayos, cit. nota $\mathrm{n}^{\circ} 31$. 
MUÑOZ, Julián Andrés. "Expertos y política criminal en Colombia".

La justificación de la convocatoria de las comisiones, se suele justificar también por razones que miran hacia el pasado: la necesidad de evaluar el impacto de unas determinadas intervenciones o programas jurídico penales, y la idea de que esa evaluación permitiría orientar la toma de decisiones, recomponer el rumbo o hacer coherente la política criminal.

El trabajo de cada comisión suele ser evaluado mediante una comparación o un "salto" entre el diagnóstico que ellas ofrecen, las recomendaciones que formulan y las condiciones de realidad persistentes a lo largo del tiempo. Por eso tal vez la versión más simple de la justificación de cada nueva comisión, suele ser expuesta en cada momento por los discursos gubernamentales de manera bastante pragmática: las propuestas formuladas hasta el momento para combatir la violencia y la criminalidad, han sido ineficaces.

\subsection{Condiciones o carácter de los expertos.}

Los expertos no solo requieren ciertos conocimientos, sino también una cierta cercanía con quienes tienen la capacidad de convocar o de designar comisiones. Dos personas convocadas recientemente a ese tipo de comisiones ${ }^{33}$ señalan tres condiciones necesarias para que el llamado se produzca: a) Tener cercanía con círculos académicos con los cuales una determinada administración tiene "sintonía". b) Tener un conocimiento especializado que "lo muestre" como experto en una materia. c) Mantener siempre "buenas relaciones con esa administración" 34 .

Si se consulta la trayectoria de las personas que han integrado las "comisiones" objeto de estudio, puede advertirse que la profesión y la pertenencia a una determinada organización (política, eclesiástica, académica) pueden ser circunstancias que incrementan la posibilidad de adquirir el carácter de "experto" por la vía de la convocatoria directa a una comisión 35 .

Entre comisión y comisión, sin embargo, hay diferencias en lo que respecta al perfil de sus integrantes. Mientras en la Comisión Investigadora estaba integrada por miembros con vínculos estamentales más "tradicionales" (iglesia, partidos, fuerzas militares), el grupo redactor de "La Violencia en Colombia" estaba integrado por personas más cercana al mundo académico, aunque vinculadas todavía a los círculos académicos más centralizados $^{36}$. Por su parte, algunos de los expertos en economía (del crimen) estuvieron vinculados a universidades privadas. Según dos de los expertos consultados ${ }^{37}$, vale la pena reflexionar sobre esa situación, pues hace ya un buen tiempo que la definición de lo público se está encargando prioritariamente a actores que no necesariamente responden al interés general.

Formar parte de una comisión puede significar no solo "un punto de llegada", sino sobre todo un importante "punto de partida" en la trayectoria de los comisionados. De una parte,

\footnotetext{
${ }^{33}$ Experto 2, entrevistado el 14 de abril de 2015 y Experto 3, entrevistado el 16 de abril de 2015.

${ }^{34}$ Experto 2, cit. nota $\mathrm{n}^{\mathrm{o}} 33$.

${ }^{35}$ Véase el recuadro "Comisiones y expertos. Trayectorias", incluido al final del artículo.

${ }^{36}$ Particularmente al departamento de sociología de la Universidad Nacional de Colombia. Gran parte de los

"violentólogos" hacía parte del Instituto de Estudios Políticos y Relaciones Internacionales -IEPRI- también de aquella Universidad.

${ }^{37}$ Experto 4, entrevistado el 14 de abril de 2016 y Experto 5, entrevistado el 15 de abril de 2016.
} 
Polít. crim. Vol. 12, No 23 (Julio 2017), Art. 8, pp. 267-290.

[http://www.politicacriminal.cl/Vol_12/n_23/Vol12N23A8.pdf]

la publicación de los informes de las comisiones otorga una gran visibilidad a los autores, lo cual imprime un sello casi indeleble a su carácter -experto- ${ }^{38}$. De otra parte, la participación en las comisiones de expertos propicia por sí misma una notoria movilidad de los comisionados hacia cargos de dirección en la burocracia estatal (Ministros, por ejemplo) y hacia prestigiosas posiciones en el sector privado (consultores o asesores de agencias internacionales, por ejemplo).

\subsection{Potencialidad del dictamen de los expertos.}

Las comisiones han formulado un considerable catálogo de recomendaciones. Se destacan las referidas al combate de la impunidad, a la criminalización de algún comportamiento, al régimen de penas, a la eficiente administración de justicia, a la reforma del sistema penitenciario o de las condiciones carcelarias, a la ley procesal, la justicia juvenil y la policía judicial.

Si el conocimiento producido por el experto coincide con el interés de quien lo ha convocado, entonces este puede fundamentar sus decisiones con aquel dictamen. Si por el contrario, las conclusiones o recomendaciones de los expertos no apuntan a lo que proyectó el convocante, entonces no se conocerán o se ocultarán los resultados de la labor del experto $^{39}$.

Es posible que las recomendaciones de los expertos no tengan un impacto inmediato, sino más bien de mediano y largo plazo. Un "impacto retardado, que la cultura va asimilando" 40. En casos excepcionales, los expertos pueden manifestar su "decepción" o su molestia por el uso que se hizo de su trabajo ${ }^{41}$.

\subsection{Sobre enfoques o perspectivas.}

Las comisiones suelen dedicar buena parte de su tiempo a señalar las insuficiencias metodológicas, las limitaciones derivadas de compromisos disciplinares o inclusive los sesgos ideológicos de los estudios que les preceden. Se trata no solo de un ejercicio de autojustificación que cada comisión con respecto a su convocatoria, sino del uso de la ventaja que otorga la posición de "experto reconocido" en la "batalla" por la verdad o por el posicionamiento de una disciplina o de un enfoque. De hecho, entre comisión y comisión se suele producir una especie de "cambio de paradigma nacional" en el estudio del crimen y la violencia.

\footnotetext{
${ }^{38}$ Inclusive el hecho de haber integrado una comisión, puede incrementar las probabilidades de ser convocado a otra. El Experto 4, cit. $\mathrm{n}^{\mathbf{0}} 37$, por ejemplo, fue convocado para que integrara una Comisión en 1986 y veintiséis años después, en 2012, para liderar el equipo que preparó el informe final de otra comisión.

${ }^{39}$ Experto 1, entrevistado el 10 de abril de 2015.

${ }^{40}$ Experto 5, cit. nota $n^{\circ} 37$.

${ }^{41}$ Germán Guzmán, miembro de la Comisión Investigadora de las Causas de la Violencia convocada en 1958, aseguraría casi tres décadas después que la creación de esa comisión fue un acto de "demagogia marrullera", un intento de "legitimar el Frente Nacional" e "impedir la toma del poder por el pueblo". SÁNCHEZ, Gonzalo; PEÑARANDA, Ricardo, Pasado y presente de la violencia en Colombia, Bogotá: CEREC, 1986, pp. 349-366.
} 
MUÑOZ, Julián Andrés. "Expertos y política criminal en Colombia".

El giro que dan en los expertos en sus explicaciones, es llamativo. Así, en La Violencia en Colombia, las explicaciones estuvieron asociadas a la quiebra de la justicia, la ineficacia y el "utopismo" de las normas orientadas a preservar el orden, y a la responsabilidad de las élites en la propagación de la violencia. En Colombia. Violencia y Democracia, el crimen y la violencia se explicaban por causas objetivas de tipo estructural, cuyo origen se inscribe en procesos históricos de larga duración. Los expertos cercanos a la perspectiva económica del crimen, por su parte, sugieren una nueva racionalidad; pero una racionalidad según la cual no solo se puede saber del fenómeno criminal y la violencia desde la economía como disciplina, sino que el análisis de costos y beneficios ha de ser adoptado por otras disciplinas (ciencia política, derecho, sociología) como criterio de validación de sus hipótesis teóricas e investigaciones empíricas.

\section{La penalidad "influenciada" por los expertos.}

La larga duración de la confrontación armada en Colombia hace que la relación entre guerra y derecho no pueda ser claramente concebida como una relación antitética ${ }^{42}$. Al revisar la legislación penal en los períodos ya indicados, se encuentra una especie de coexistencia entre guerra, derecho y política. En otras palabras, aunque la estatalidad colombiana esté aún en construcción o aunque no haya logrado instituir monopolios -sobre tributos, movilidad de personas y recursos o sobre el castigo-, eso no implica que el derecho no exista o que no se produzcan normas jurídicas por procedimientos preestablecidos y autoridades competentes.

De hecho, la propia guerra -o las guerras- contra diversos enemigos se han librado en Colombia no sólo por las armas sino también recurriendo al derecho ${ }^{43}$. Así, por ejemplo, a los enemigos partidistas en la década de los años 40-50 se les quiso derrotar a través de las normas penales, tanto como la guerra contra el comunismo o la subversión del período de la Guerra Fría, o la guerra contra el narcotráfico de las últimas décadas del siglo, se quisieron ganar con extensos y especiales cuerpos normativos penales ${ }^{44}$. En síntesis, como señala Muñoz, el ejercicio de poder político frente al fenómeno criminal en Colombia (la política criminal) se ha orientado a la derrota de enemigos cuya "fisonomía" ha variado mientras las prácticas punitivas para derrotarlos se mantienen constantes ${ }^{45}$.

Pero además, como han mostrado Pérez y otros, por lo menos desde mediados del siglo XX los gobiernos colombianos han hecho un uso constante del estado de excepción para enfrentar a cada sujeto y situación considerados críticos. A diferencia de las leyes

\footnotetext{
${ }^{42}$ En el imaginario construido por el pensamiento hobbesiano o por el mito del contrato social, el derecho $-\mathrm{y}$ el Estado- sólo pueden existir en condiciones de negación de la guerra; o dicho de otra manera, sólo en condiciones de paz sería posible hablar de Estado y de Derecho.

${ }^{43}$ MUÑOZ, Julián, Saber y poder en la política criminal de la seguridad democrática, 2002-2006. Medellín: Facultad de Derecho y Ciencias Políticas-Universidad de Antioquia, 2015, pp. 12, 40-63.

${ }^{44}$ Un "Estatuto de Seguridad" para los insurgentes (o sospechosos de serlo); un "Estatuto para la Defensa de la Democracia" para los narcotraficantes (y afines); un "Estatuto para la Defensa de la Justicia" para todos los anteriores, y un "Estatuto antiterrorista" para los -imprecisables- terroristas. Véase: ITURRALDE, Manuel, Castigo, liberalismo autoritario y justicia penal de excepción, Bogotá: Siglo del Hombre - Universidad de los Andes, 2010, pp. 55-111. Igualmente: MUÑOZ, Saber y poder, cit. nota n 43, pp. 145-166.

${ }^{45}$ MUÑOZ, Saber y poder, cit. nota ${ }^{\circ} 43$, pp. 40-58.
} 
Polít. crim. Vol. 12, No 23 (Julio 2017), Art. 8, pp. 267-290.

[http://www.politicacriminal.cl/Vol_12/n_23/Vol12N23A8.pdf]

tramitadas en los parlamentos, los "decretos legislativos" expedidos por el gobierno para responder desafíos inminentes a la estabilidad institucional, se sancionan, promulgan y aplican vertiginosamente ${ }^{46}$ con la idea de que así se conjura también rápidamente la amenaza de la que se trate (aunque ella sea tan imprecisa como "la subversión" o "el terrorismo").

El reiterado recurso a la legislación “de emergencia” en Colombia, ha producido en el largo plazo la normalización de ese dispositivo extraordinario en que consisten los estados de excepción ${ }^{47}$. La actuación urgente del ejecutivo en la producción de la ley o, lo que es lo mismo, el déficit deliberativo en la producción del derecho, se ve reforzada por la frecuente expedición de leyes de facultades que "en tiempos de paz" trasladan al gobernante la facultad legislativa. La excepción es por eso, en síntesis, un rasgo que define el modelo de política criminal en Colombia.

Así, en todos los períodos de los cuales se ocupó esta investigación, la mayoría de las normas penales expedidas fueron decretos del ejecutivo. Se trata de una práctica que en su momento contravenía las recomendaciones de los expertos autores de "La Violencia en Colombia" y de la comisión que produjo el informe "Colombia. Violencia y Democracia".

Por cada período de los que aquí interesan, esa práctica excepcional de producción del derecho penal tiene el siguiente comportamiento: En el período comprendido entre los años 1965 y 1987, primer corte temporal de la investigación, de las 140 normas penales expedidas sólo 5 corresponden a leyes tramitadas en el Congreso $(3.5 \%)$.

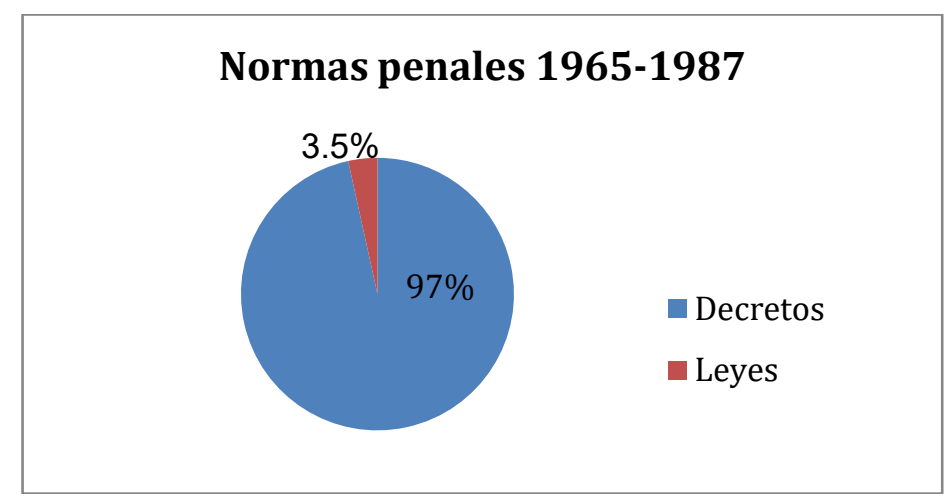

En el período que va de 1988 a 1995, el número de normas debatidas en el Congreso de la República se incrementa un poco. De 139 normas expedidas, 8 son leyes. Las demás, decretos presidenciales:

\footnotetext{
${ }^{46}$ PÉREZ, William; VANEGAS, Alba; ÁLVAREZ, Carlos, Estado de Derecho y sistema penal. Medellín: Biblioteca Jurídica Diké-Universidad de Antioquia, 1997.

${ }^{47}$ PÉREZ/VANEGAS/ÁLVAREZ, Estado de derecho, cit. nota n ${ }^{\circ} 46$.
} 
MUÑOZ, Julián Andrés. "Expertos y política criminal en Colombia".

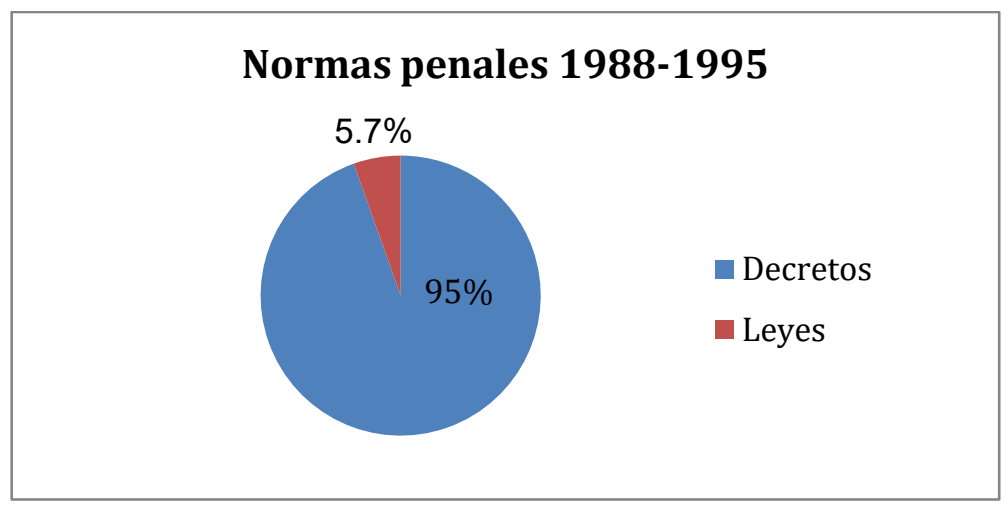

Finalmente, entre los años 1996 y 2000, todas las normas penales analizadas (13) fueron expedidas por el Congreso bajo la modalidad de leyes ordinarias. Esta última -y radicalvariación en las formas y autoridades que producen la ley a partir de 1995, obedece básicamente al impacto inmediato de una nueva Constitución Política sancionada en 1991. Esta Constitución limitó el uso de los estados de excepción con la indicación detallada de sus tipologías, con la imposición de límites temporales y con el mandato de una ley estatutaria que regulara en detalle procedimientos, competencias y controles. Así por ejemplo, a diferencia del ilimitado estado de sitio de la Constitución precedente (de 1886), el estado de conmoción interior que consagró la Constitución de 1991 sólo puede ser decretado durante lapsos de tiempo precisos, e inclusive una de sus prórrogas debe ser autorizada por el Senado.

Con todo, el nuevo orden constitucional no pudo contener "prácticas de excepción" nuevamente caracterizadas por el cierre de la deliberación pública. Estas prácticas van desde la reforma constante del propio referente constitucional de 1991, pasando por la avasallante prevalencia de la iniciativa ejecutiva en proyectos de ley penal, hasta la taimada- expedición de normas penales mediante la declaración de estados de excepción ajenos a la idea de "la ciudad sitiada" (emergencias económicas, financieras, invernales o de salud) ${ }^{48}$. Así, que las normas se vuelvan a expedir a voluntad del ejecutivo, hace que se las sustraiga nuevamente del debate público. En la reforma de la ley penal no intervienen los órganos colegiados de representación política, o intervienen solo a instancias del ejecutivo y una vez que "la coalición de gobierno" ha pactado su aprobación. No existe manera de conocer las motivaciones de la decisión más allá de los "considerandos" formales que aparecen en los textos una vez expedidos.

En relación con el problema que interesa en este texto, no es extraño entonces que los diagnósticos o recomendaciones de los grupos de expertos en materia de política criminal no sean acatados en casos de decisiones "de emergencia". La labor de esos grupos o comisiones de expertos requiere un tiempo mucho mayor del que exige el diseño de fórmulas precipitadas para enfrentar coyunturas definidas como críticas. A los regímenes u órdenes "de excepción", por eso, les resultan más adecuadas las figuras del "consejero" o del "asesor" (para la paz, para la guerra, para el orden público, para el combate de las

\footnotetext{
${ }^{48}$ PÉREZ, William, "El estado de excepción es lo de menos", en: MONTOYA, Mario; MONTOYA, Nataly (Eds.), Reflexiones constitucionales: a propósito de dos décadas de la Constitución en Colombia, Medellín: Fondo Editorial Eafit, 2012, pp. 203-232.
} 
Polít. crim. Vol. 12, № 23 (Julio 2017), Art. 8, pp. 267-290.

[http://www.politicacriminal.cl/Vol_12/n_23/Vol12N23A8.pdf]

drogas). Una coalición interpartidista urgente puede ser también un sustituto suficiente de las comisiones de expertos, para definir la ruta de "superación de la crisis".

Si se tienen en mente esas inferencias, no sorprende entonces que al revisar el derecho penal producido en Colombia durante los períodos mencionados, no se encontró ninguna alusión expresa a las recomendaciones que formularon las comisiones de expertos autoras de los informes "La Violencia en Colombia" y "Colombia. Violencia y Democracia"; o que tampoco sean citados los trabajos sobre violencia y crimen que, con un enfoque económico, se realizaron y publicaron desde la segunda mitad de la década de los noventa ${ }^{49}$. Mucho menos se encontró evidencia concluyente que permita afirmar una incidencia inmediata y directa de las recomendaciones de esos grupos de expertos en la política criminal. Inclusive en algunos casos es posible que se haya hecho todo lo contrario ${ }^{50}$.

Sin embargo, aunque aquella contrastación "simple" insinúe que definitivamente no hay conexión entre saberes expertos y poder político, por lo menos en el caso de la política criminal, conviene no olvidar lo siguiente:

- Que es un hecho que los políticos sí recurren a los expertos para que diagnostiquen y expliquen problemas referidos a la cuestión criminal, o para que formulen recomendaciones que faciliten su solución. De esto dan cuenta la existencia de comisiones y expertos como los mencionados, y los que en lo sucesivo fueron convocados o consultados por el gobierno nacional en relación con las drogas, la prisión perpetua, la política criminal en general o el origen y la pervivencia del conflicto armado en Colombia 51 . Un problema distinto es "el uso" político (previo, inmediato o de largo plazo) que se hace del trabajo de esos expertos

- Que aunque se trate de una "comisión redactora", por lo menos para la expedición del Código Penal de $1980^{52}$ se acogieron plenamente las recomendaciones de una comisión

\footnotetext{
${ }^{49}$ Esto no significa que ninguna recomendación haya sido tenida en cuenta en otros temas. Las Comisiones analizadas, sugirieron acciones en otros campos. Solo un ejemplo: "Colombia. Violencia y Democracia" formuló recomendaciones derivadas de su diagnóstico sobre "las causas objetivas" del crimen y la violencia, las cuales se tradujeron en programas del Plan Nacional de Rehabilitación y en estrategias de seguridad en ciudades como Bogotá, Medellín y Cali. Véase a ese respecto: CASTRO, Manuel; FERRO, Manuel, La respuesta a la criminalidad y la violencia en Colombia. Acciones del Estado para promover la convivencia y la seguridad en las ciudades, Trabajo preparado para la conferencia "Violence in Latin America: Policy Implications from Studies on the Attitudes and Costs of Violence", Universidad de Harvard, Cambridge-MA, Febrero 19-20, 1998, en: http://www.fuac.edu.co/download/AREAS/7vc.pdf, [visitado 14.07.2016].

${ }^{50}$ Por lo menos si se consideran algunas recomendaciones sobre la limitación a los estados de excepción y el respeto de las libertades civiles, es constatable que en esos períodos se incrementaron las restricciones a los derechos y se siguieron concentrando funciones en cabeza del ejecutivo ARBELÁEZ, La legislación, legislación penal en Colombia (1962-1980): arma estatal para enfrentar al enemigo, trabajo presentado para optar al título de Politólogo, Universidad de Antioquia, Medellín, 2016, pp. 20-21.

${ }^{51}$ Sobre la relevancia de la cuestión criminal en los dictámenes expertos sobre la violencia y la guerra en Colombia, véase: DUNCAN, Gustavo, "Exclusión, insurrección y crimen", en: COMISIÓN HISTÓRICA DEL CONFLICTO Y SUS VÍCTIMAS, Contribución al entendimiento del conflicto armado en Colombia. Bogotá, 2015, pp. 249-294.

${ }^{52}$ ARBELÁEZ, La legislación, cit. nota no 50, pp. 26-27.
} 
MUÑOZ, Julián Andrés. "Expertos y política criminal en Colombia".

que sesionó durante seis años (entre 1972 y 1978) ${ }^{53}$, convocada por el Gobierno Nacional. Así que los expertos, por lo menos aquellos que integran comisiones redactoras de códigos, pueden llegar a incidir en el diseño de la política criminal (así sea después de un dilatado trabajo).

- Que podría haber una conexión entre las recomendaciones de la comisión de los "violentólogos" de finales de los años ochenta, y la creación del delito de "Violencia intrafamiliar" en la segunda mitad de la década siguiente (artículo $9^{\circ}$ de la ley 294 de 1996). La violencia, afirmaban los violentólogos, no surge principalmente de antagonismos políticos ni se expresa mayoritariamente en notorios acontecimientos o grandes crímenes, sino que se presenta sobre todo en relaciones y en escenarios ordinarios. Este delito de violencia intrafamiliar podría concretar esa idea. Como sugirió uno de los expertos que integraron esta comisión, el impacto de las comisiones puede incidir a largo plazo en la cultura.

- Que la perspectiva económica del crimen (1995-2000), conforme a la cual el comportamiento criminal es ante todo el resultado de una elección racional, hizo hincapié en la necesidad de combatir el crimen organizado. Es posible que los mecanismos de justicia premial ${ }^{54}$ que atraviesan el código de procedimiento penal del año 2000 (ley 600), pudieran estar inspirados en aquellas ideas de los economistas del crimen. Principios de "eficiencia" y proliferación de incentivos en la lucha contra la impunidad, pudieron haberse concretado en ese código y sobre todo en las reformas posteriores (como las leyes 890 y 904 de 2004, que sin embargo no fueron objeto de la investigación).

- Que en niveles territoriales más localizados (Municipios y Departamentos), la presencia de expertos directamente involucrados con el diseño de las políticas de seguridad son un hecho constatable por lo menos desde finales de la década del noventa. La financiación de programas específicos de seguridad ciudadana por el Banco Interamericano de Desarrollo en las principales ciudades de Colombia, puede haber sido un momento inaugural de la relación directa entre expertos y gobernantes para el diseño de esa especie de macro-política o de política transversal que representa hoy una política de seguridad. Y aunque durante los primeros años de la década de 2000 esos expertos tampoco solían ser citados en los documentos oficiales de las

\footnotetext{
${ }^{53}$ Código Penal expedido mediante Decreto-ley 100 de 1980 (según facultades otorgadas por la ley 5 de 1979).

${ }^{54}$ Por ejemplo, el artículo 413 de la ley 600, por medio de la cual se expidió el Código de Procedimiento Penal, reguló el "beneficio por colaboración”, según el cual se podría conceder: “( ...) acumulativamente y en razón del grado de colaboración, una disminución de una sexta (1/6) hasta una cuarta (1/4) parte de la pena que corresponda al sindicado en la sentencia condenatoria, sustitución de la prisión por prisión domiciliaria, suspensión condicional de la ejecución de la pena o la libertad condicional en los términos previstos en el Código Penal e incorporación al programa de protección a víctimas y testigos". Sobre justicia premial en Colombia, ver: GONZÁLEZ, Julio, “¿Qué pasa con la pena hoy en día?”, Diálogos de Derecho y Política, Año 3, $\mathrm{n}^{\mathrm{o}} 9$ (2012), pp. 1-13. Versión online disponible En: http://aprendeenlinea.udea.edu.co/revistas/index.php/derypol/article/viewFile/12318/11167 [visitado el 14.07.2016].
} 
Polít. crim. Vol. 12, № 23 (Julio 2017), Art. 8, pp. 267-290.

[http://www.politicacriminal.cl/Vol_12/n_23/Vol12N23A8.pdf]

administraciones públicas locales ${ }^{55}$, la situación ha ido cambiando progresivamente. El sello de organizaciones - expertas- internacionales o de "centros de pensamiento" nacionales y locales, se hacen cada vez más -deliberadamente- visibles en la política de seguridad que adoptan esos gobiernos ${ }^{56}$. La incidencia o el impacto de las recomendaciones de los expertos, por lo tanto, se pueden apreciar con mayor facilidad en el campo de la seguridad y en esos niveles locales.

- Que pese a la imposibilidad jurídica de que en esos niveles territoriales se definan delitos, penas o términos procesales, allí mismo sí puede darse una importante incidencia en el orden de las prioridades político criminales del Estado. Por ejemplo, mediante la destinación de recursos locales al fortalecimiento de la administración de justicia penal; el diseño, evaluación y apoyo a programas específicos de vigilancia y reacción policial; la definición y persecución de desórdenes e incivilidades ("contravenciones de policía", en el lenguaje jurídico colombiano) ${ }^{57}$; la financiación de programas de prevención o reacción soportados en tecnologías de seguridad; la cofinanciación de prisiones; la prevalencia de los diagnósticos "criminológicos" que adelantan los propios gobiernos municipales y departamentales, o la preferencia por las decisiones de los Consejos de Seguridad locales en relación con "delitos de impacto", "blancos sensibles", "puntos críticos", "poblaciones de riesgo", etc. ${ }^{58}$.

\section{Conclusiones y discusiones.}

El objetivo de esta indagación, se reitera, fue analizar el impacto de las recomendaciones de los expertos en el diseño de la política criminal. Se analizaron tres períodos en los cuales se pretendió establecer si -y cómo- las recomendaciones de los expertos incidieron en el diseño de la política criminal en Colombia. Los hallazgos más destacables de esa búsqueda fueron expuestos en el apartado final del texto. Por eso ahora se enlistan algunas

\footnotetext{
${ }_{55}^{55}$ Experto 1, cit. nota $\mathrm{n}^{\circ} 39$.

${ }^{56}$ Entre los años 1998 y 2000, en la ciudad de Bogotá se adoptaron con entusiasmo "la teoría de las ventanas rotas" y las ideas político-criminales de "la tolerancia cero". "Broken Windows" es una teoría de los años 80 según la cual un desorden no intervenido a tiempo puede derivar en desórdenes mayores, en una secuencia que conducirá finalmente al crimen. WILSON, James; KELLING, George, "Ventanas rotas: la policía y la seguridad en los barrios", FRIDMAN, Daniel (Trad.), Delito y sociedad. Revista de ciencias sociales, $\mathrm{n}^{\circ} 15-$ 16 (2001), pp. 67-79. Como "Zero Tolerance" se reconoce el conjunto de estrategias de control policial desplegadas durante la administración de Rudolph Giuliani en la ciudad de New York. Una crítica a su carácter racista y represivo, puede verse en: WAQUANT, Löic, Las cárceles de la miseria, PONS, Horacio (Trad.), Buenos Aires: Manantial, 2004, p. 38.

${ }_{58}^{57}$ Artículo 315, numeral 2 Constitución Política de Colombia.

${ }^{58} \mathrm{Al}$ respecto, son elocuentes las estrategias preventivas en Bogotá y Medellín. Aunque según Llorente \& Guarín, (2013), las medidas locales de seguridad ciudadana no explican la reducción de la criminalidad en esas ciudades durante los años 90 y buena parte de 2000. LLORENTE, María; GUARÍN, Sergio,"Colombia: éxitos y leyendas de los "modelos" de seguridad ciudadana: Bogotá y Medellín", en: BASOMBRIO, Carlos (Coord.), ¿A dónde vamos? Análisis de políticas públicas de seguridad en América Latina. Washington: Woodrow Wilson International Center for Scholars, 2013, pp.169-202. Cfr: ACERO, Hugo, Respuesta al estudio "Colombia: éxitos y leyendas de los "modelos" de seguridad ciudadana: los casos de Bogotá y Medellín, 2014, disponible en: https://www.wilsoncenter.org/sites/default/files/Respuesta\%20al\%20estudio $\% 20 \mathrm{de} \% 20$ Llorente $\% 20 \mathrm{y} \% 20 \mathrm{Gu}$ arin_0.pdf [visitado el 14.07.2016].
} 
MUÑOZ, Julián Andrés. "Expertos y política criminal en Colombia".

conclusiones más generales, y se dejan sugeridas algunas discusiones sobre la relación entre política criminal y conocimiento experto.

a) A pesar de la fuerte creencia del positivismo científico del siglo XIX en la objetividad y avaloratividad del cocimiento científico, hoy esa idea es insostenible ${ }^{59}$. En la formación de las ciencias sociales no solo hay interés por resolver problemas de la sociedad, pues el conocimiento de la ciencia sirve también al objetivo de justificar o inducir relaciones de poder.

b) La demanda política de saberes especializados en violencia y criminalidad -y por lo tanto una más estrecha relación entre expertos y políticos-, coincide en Colombia con el período del Frente Nacional (1948-1974); es decir, con un régimen al que se suele asociar con la modernización del Estado y la pacificación del país ${ }^{60}$.

c) A pesar de que en la legislación penal revisada entre los años 1962 y 2000 no se encontraron elementos que prueben un impacto directo de las recomendaciones de los expertos, sería simplista afirmar que su impacto fue nulo.

d) La relación entre expertos y decisiones políticas por la vía de la convocatoria de comisiones como las que han sido abordadas en este trabajo, puede rastrearse con dificultad y las conclusiones al respecto tienen todavía un marcado carácter hipotético. En esa dificultad posiblemente incida el hecho de que la guerra ha hecho parte del contexto en el cual se convocan las comisiones de expertos. Ya se trate de una confrontación concluida (como sucedió con la Comisión de 1958) o de un conflicto armado en curso (como en los demás casos), la guerra se ha constituido en un estado de $\operatorname{cosas}^{61}$ en torno al cual se han construido las diversas interpretaciones de los expertos.

e) Es muy probable que en el futuro inmediato aquella relación entre expertos y política criminal se afiance y que pueda ser más claramente documentable el impacto de sus recomendaciones. No solo porque el conflicto armado colombiano parece tener actualmente un punto de quiebre importante, sino porque se ha producido recientemente una especie de centralización de "las comisiones de expertos" relacionadas con la política criminal. El decreto 2055 de 2014, reglamentó el Consejo Superior de Política Criminal y creó con carácter permanente la Comisión Asesora de Política Criminal. Entre las funciones que se le asigna a este último organismo, se encuentran la de "adelantar estudios e investigaciones sobre las causas y las consecuencias del fenómeno criminal en Colombia".

f) Un reciente pronunciamiento de la Corte Constitucional (sentencia T-762 de 2105), adicionalmente, ordena que las reformas penales cuenten con un concepto del Comité Técnico del Consejo Superior de Política Criminal. Es decir que, por lo menos en los

\footnotetext{
${ }^{59}$ DE LA CORTE, Luis, "Apuntes sobre ética y ciencia social: A vueltas con la cuestión del compromiso". Revista de Ciencias Sociales y Humanidades, $\mathrm{n}^{\circ} 100$ (2004), pp. 421-459; BORDIEU, Pierre, Intelectuales, política y poder, Buenos Aires: Eudeba, 2014, p. 76.

${ }^{60}$ A esta conclusión llega también, por cierto, el más reciente informe de la Comisión Histórica del Conflicto en Colombia PECUT, Daniel, "Una lucha armada al servicio del statu quo social y político", en: COMISIÓN HISTÓRICA DEL CONFLICTO Y SUS VÍCTIMAS, Contribución al entendimiento del conflicto en Colombia, disponible en: https://www.mesadeconversaciones.com.co/sites/default/files/Informe\%20Comisi_n\%20Hist_rica\%20del\%20 Conflicto\%20y\%20sus\%20V_ctimas.\%20La\%20Habana\%2C\%20Febrero\%20de\%202015.pdf [visitado el 14.07.2016].

${ }^{61}$ URIBE, María Teresa, "Las soberanías en vilo en un contexto de guerra y paz", Estudios Políticos, n ${ }^{\circ}$ 13(1998), pp. 11-37.
} 
Polít. crim. Vol. 12, № 23 (Julio 2017), Art. 8, pp. 267-290.

[http://www.politicacriminal.cl/Vol_12/n_23/Vol12N23A8.pdf]

términos de la ley, se ha dispuesto que el saber de los expertos sea un condicionante del diseño de las normas penales. La decisión de la Corte prescribe que el diseño de la política criminal cuente con una base empírica que permita hacer seguimiento al impacto de las reformas.

g) Lo que está por verse, no obstante, es si esta decisión judicial logrará librar a las reformas penales -y a qué costo- de la lógica populista y demagógica con la cual algunos políticos refuerzan su trabajo de marketing. Como algunos autores han advertido, el rol de los expertos puede tener un efecto de contención de impulsos punitivistas $^{62}$; pero como otros estudiosos sugieren, el protagonismo de los expertos puede erosionar la deliberación y, por tanto, derivar la discusión (sobre qué castigar y cómo hacerlo) a un ámbito cada vez menos democrático, más administrativo y "técnico"63.

h) En el contexto de un eventual pos acuerdo ${ }^{64}$ surgido de las negociaciones que se desarrollan en La Habana entre el Gobierno Nacional y la guerrilla de las Fuerzas Armadas Revolucionarias de Colombia, FARC-EP (y las que posiblemente se adelanten con el Ejército de Liberación Nacional, ELN), cabría preguntar: ¿cuál será el rol de los expertos en el diseño de la política criminal? ¿Qué tipo de recomendaciones son adecuadas para un escenario de transición? ¿Es conveniente, en la posguerra, más o menos participación ciudadana en la discusión de los contenidos de la ley penal? ¿Cómo se conducirán, y según la perspectiva de cuáles expertos, los regímenes diferenciados de la ley penal para combatientes, no combatientes o población civil?

\footnotetext{
${ }^{62}$ LARRAURI, Elena: "Populismo punitivo...y cómo resistirlo", Jueces para la Democracia, $\mathrm{n}^{\circ} 55$ (2006), pp. 15-22; SOTOMAYOR, Juan, "Las recientes reformas penales en Colombia: un ejemplo de irracionalidad legislativa", Nuevo Foro Penal, no 71(2007), pp. 13-66; COMISIÓN ASESORA DE POLÍTICA CRIMINAL, Informe Final, cit. nota ${ }^{\circ} 2$.

${ }^{63}$ PÉREZ, "El Estado", cit. nota no 48, pp. 203-232.

${ }^{64}$ Más que un "pos-conflicto", lo que cabe esperar una vez formados los acuerdos entre las partes es un escenario en el cual se el conflicto florezca pero ya sin que su tramitación pase por la guerra.
} 
MUÑOZ, Julián Andrés. "Expertos y política criminal en Colombia".

Anexo:

Comisiones y expertos. Trayectorias

\begin{tabular}{|c|c|c|c|}
\hline & Miembro/Experto & Trayectoria & Publicaciones \\
\hline \multirow{7}{*}{ 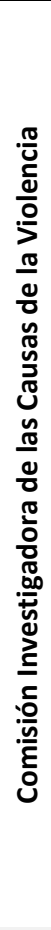 } & Otto Morales B. & $\begin{array}{l}\text { Miembro del partido Liberal; Ministro } \\
\text { del Trabajo (1959 y 1960; Profesor } \\
\text { universitario; Congresista; Diputado } \\
\text { Asamblea Departamental; Miembro } \\
\text { Academia Colombiana de Historia y } \\
\text { Academia Colombiana de la Lengua }\end{array}$ & $\begin{array}{l}\text { Aguja de Marear (1979); Muchedumbres y } \\
\text { banderas: luchas por la libertad (1980); Derecho } \\
\text { agrario y otros temas de la tierra (1981); Cátedra } \\
\text { caldense (1984). }\end{array}$ \\
\hline & $\begin{array}{l}\text { Absalón } \\
\text { Fernández }\end{array}$ & $\begin{array}{l}\text { Miembro del partido Liberal; Ministro } \\
\text { de Gobierno (1934); Gobernador } \\
\text { (1944-1945; 1958-1959); Procurador } \\
\text { General de la Nación (1936-1937); } \\
\text { Magistrado Corte Suprema de Justicia, } \\
\text { Sala Penal (1940-1942) }\end{array}$ & $\begin{array}{l}\text { El estatuto de los empleados particulares ante los } \\
\text { derechos adquiridos; Las garantías } \\
\text { constitucionales en el proceso penal }\end{array}$ \\
\hline & $\begin{array}{l}\text { Augusto Ramírez } \\
\text { M. }\end{array}$ & $\begin{array}{l}\text { Miembro del partido conservador; } \\
\text { Ministro de Gobierno (1960-1961); } \\
\text { Miembro del Directorio Nacional } \\
\text { Conservador; Embajador }\end{array}$ & $\begin{array}{l}\text { "El político" (1931); "Los Leopardos" (1935); “Las } \\
\text { ideas socialistas y el problema presidencial” } \\
\text { (1937); "La crisis del partido conservador en } \\
\text { Colombia"; "La nueva generación" (1966); } \\
\text { "Dialéctica anticomunista" (1973), }\end{array}$ \\
\hline & Ernesto Caicedo L. & $\begin{array}{l}\text { General, Jefe estado mayor FFMM; } \\
\text { Gobernador (1957-1958) }\end{array}$ & \\
\hline & $\begin{array}{l}\text { Hernando Mora } \\
\text { A. }\end{array}$ & General $(r)$ de las Fuerzas Militares & \\
\hline & Fabio Martínez & Sacerdote (Párroco) & \\
\hline & $\begin{array}{l}\text { Germán Guzmán } \\
\text { C. }\end{array}$ & Sacerdote (Monseñor) & “La Violencia en Colombia”, tomos I y II \\
\hline \multirow{3}{*}{ 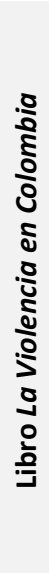 } & Eduardo Umaña L. & $\begin{array}{l}\text { Locutor de la Radio Nacional; } \\
\text { Subdirector de la Biblioteca Nacional; } \\
\text { Decano Facultad de Sociología, } \\
\text { Universidad Nacional de Colombia } \\
\text { (1974-1975; 1984-1986) }\end{array}$ & $\begin{array}{l}\text { "La Violencia en Colombia", tomos I y II; La } \\
\text { violencia y la paz. Los delitos políticos, las } \\
\text { amnistías y los presos políticos (1982); Camilo y el } \\
\text { nuevo humanismo (2003) }\end{array}$ \\
\hline & $\begin{array}{l}\text { Germán Guzmán } \\
\text { C. }\end{array}$ & Sacerdote (Monseñor) & "La Violencia en Colombia", tomos I y II \\
\hline & Orlando Fals B. & $\begin{array}{l}\text { Decano Facultad de Sociología; } \\
\text { Consultor de la OEA en Brasil; Director } \\
\text { general (Viceministro) Ministerio de } \\
\text { Agricultura (1959-1961); Delegado de } \\
\text { la Alianza Democrática M-19 para la } \\
\text { redacción de la Constitución Política de } \\
\text { 1991; Secretario General Comisión de } \\
\text { Ordenamiento territorial }\end{array}$ & $\begin{array}{l}\text { "La Violencia en Colombia", tomos I y II; Historia } \\
\text { de la cuestión agraria en Colombia (1975); } \\
\text { Historia doble de la Costa; Orígenes universales y } \\
\text { retos actuales de la IAP (1998) }\end{array}$ \\
\hline
\end{tabular}


Polít. crim. Vol. 12, No 23 (Julio 2017), Art. 8, pp. 267-290.

[http://www.politicacriminal.cl/Vol_12/n_23/Vol12N23A8.pdf]

\begin{tabular}{|c|c|c|c|}
\hline \multirow{4}{*}{ 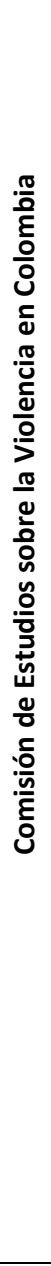 } & Gonzalo Sánchez & $\begin{array}{l}\text { Director Centro Nacional de Memoria } \\
\text { Histórica; Comisión Nacional de } \\
\text { Reparación y Reconciliación; Consejero } \\
\text { Programa de Ciencias Sociales de } \\
\text { COLCIENCIAS; Coordinador Comisión } \\
\text { de Estudios sobre la violencia en } \\
\text { Colombia }\end{array}$ & $\begin{array}{l}\text { Guerras, Memoria e Historia (2006); Museo } \\
\text { Memoria y Nación (2000); Memoria de un país en } \\
\text { guerra. Los mil días 1899-1902 (2001); Conflictos } \\
\text { regionales: la crisis del eje cafetero (1999); Guerra } \\
\text { y política en la sociedad colombiana (1991); } \\
\text { Memorias 1986-1996 (1996); Pasado y presente } \\
\text { de la violencia en Colombia (1995); Colombia, } \\
\text { Violencia y Democracia (1987); Bandoleros, } \\
\text { Gamonales y campesinos (1983); Bandits, } \\
\text { peasants and politics (2001); Los Bolcheviques del } \\
\text { Líbano (Tolima) (1976); Las Ligas Campesinas en } \\
\text { Colombia (1977); Los Días de la Revolución } \\
\text { Gaitanismo y 9 de Abril en Provincia (1983); Los } \\
\text { Días de la Revolución Gaitanismo y 9 de Abril en } \\
\text { Provincia (1984); El Marxismo en Colombia (1984); } \\
\text { Ensayos de Historia Social y Política del Siglo XX } \\
\text { (1984); Once Ensayos sobre La Violencia en } \\
\text { Colombia (1985) }\end{array}$ \\
\hline & Carlos M. Ortiz & $\begin{array}{l}\text { Integrante de la Comisión para la } \\
\text { investigación de la violencia y } \\
\text { recomendación de reformas políticas } \\
(1986-1990)\end{array}$ & $\begin{array}{l}\text { Urabá. Tras las huellas de los inmigrantes: } 1955 \text { a } \\
\text { 1990. (1998); Estado y subversión en Colombia } \\
\text { (1985); Colombia. Violencia y democracia (1987); } \\
\text { La Violencia y el municipio colombiano: 1980- } \\
1997 \text { (1997); Economía, crimen y conflicto (2001); } \\
\text { Guerra en Colombia. Actores armados; Urabá, } \\
\text { pulsiones de vida y desafíos de muerte (2007); } \\
\text { Pensar el pasado (1997); Las historia al final del } \\
\text { milenio (1995); Violence in Colombia (1992) }\end{array}$ \\
\hline & Darío Fajardo M. & $\begin{array}{l}\text { Profesor Facultad de Ciencias } \\
\text { Económicas, Universidad Nacional; } \\
\text { Programa Naciones Unidas -FAO }\end{array}$ & \\
\hline & Jaime Arocha & $\begin{array}{l}\text { Profesor, departamento de } \\
\text { Antropología, Universidad Nacional }\end{array}$ & $\begin{array}{l}\text { Utopía para los excluidos (2004); Herederos del } \\
\text { Jaguar y la Anaconda (1982); La Violencia en } \\
\text { Monteverde Quindío (1979) }\end{array}$ \\
\hline \multirow{2}{*}{ 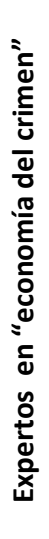 } & $\begin{array}{l}\text { Fernando Gaitán } \\
\text { D. }\end{array}$ & $\begin{array}{l}\text { Departamento Nacional de Planeación; } \\
\text { Profesor Universidad Externado de } \\
\text { Colombia }\end{array}$ & $\begin{array}{l}\text { Dos ensayos especulativos sobre la violencia en } \\
\text { Colombia (1995) }\end{array}$ \\
\hline & Mauricio Rubio & $\begin{array}{l}\text { Universidad Externado de Colombia; } \\
\text { Banco Interarmericano de Desarrollo; } \\
\text { Universidad Carlos III; Pontificia } \\
\text { Universidad Javeriana; Bolsa de } \\
\text { Bogotá; Departamento Nacional de } \\
\text { Planeación; Universidad de los Andes }\end{array}$ & $\begin{array}{l}\text { Crimen e impunidad. Precisiones sobre la } \\
\text { Violencia (1999); Del rapto a la pesca milagrosa. } \\
\text { Breve historia del secuestro en Colombia (2006); } \\
\text { De la pandilla a la mara. Pobreza, educación, } \\
\text { mujeres y violencia juvenil (2007); Pandillas, } \\
\text { rumba y actividad sexual. Desmitificando la } \\
\text { violencia juvenil (2007); Economía jurídica. } \\
\text { Introducción al análisis económico del derecho } \\
\text { iberoamericano (2007) }\end{array}$ \\
\hline
\end{tabular}


MUÑOZ, Julián Andrés. "Expertos y política criminal en Colombia".

\section{BIBLIOGRAFÍA}

ACERO, Hugo, Respuesta al estudio "Colombia: éxitos y leyendas de los "modelos" de seguridad ciudadana: los casos de Bogotá y Medellín, 2014, en: https://www.wilsoncenter.org/sites/default/files/Respuesta\%20al\%20estudio\%20de\% 20Llorente\%20y\%20Guarin_0.pdf [visitado el 14.07.2016].

ARBELÁEZ, Luis, La legislación penal en Colombia (1962-1980): arma estatal para enfrentar al enemigo, trabajo presentado para optar al título de Politólogo, Universidad de Antioquia, Medellín, 2016, pp. 20-21 (sin publicar).

BORDIEU, Pierre, Intelectuales, política y poder, Buenos Aires: Eudeba, 2014.

BOUZAS, Roberto; FFRENCH-DAVIS, Ricardo "Globalización y políticas nacionales: ¿cerrando el círculo?”, Revista de Desarrollo Económico, vol. 45, n 179 (2005), pp. 323-348.

CÁRDENAS, Mauricio; STEINER, Roberto, (Compiladores), Corrupción, crimen y justicia: una perspectiva económica, Bogotá: TM Editores, 1998.

CASTRO, Manuel; FERRO, Manuel, La respuesta a la criminalidad y la violencia en Colombia. Acciones del Estado para promover la convivencia y la seguridad en las ciudades, Trabajo preparado para la conferencia "Violence in Latin America: Policy Implications from Studies on the Attitudes and Costs of Violence", Universidad de Harvard, Cambridge-MA, Febrero 19-20, 1998, en: http://www.fuac.edu.co/download/AREAS/7vc.pdf, [visitado 14.07.2016].

COLOMER, Josep, El gobierno mundial de los expertos, Barcelona: Anagrama, 2015.

COMISIÓN ASESORA DE POLÍTICA CRIMINAL, Informe final. Diagnóstico y propuesta de lineamientos de política criminal para el Estado colombiano, 2012, en: http://www.minjusticia.gov.co/Library/News/Files/Ver\%20informe127.PDF, [visitado 4 .06.2013].

, Observaciones a la iniciativa sobre la imposición de cadena perpetua a ciertos delitos contra menores, 2011, en: https://www.ambitojuridico.com/BancoMedios/Documentos\%20PDF/conclusiones\% 20comisión\%20asesora.pdf, [visitado 22.08.2016].

COMISIÓN ASESORA PARA LA POLÍTICA DE DROGAS EN COLOMBIA, Lineamientos para una política pública frente al consumo de drogas, 2013, en: http://www.odc.gov.co/Portals/1/publicaciones/pdf/destacados/comision_asesora_pol itica_drogas_colombia.pdf, [visitado 22.08.2013].

COMISIÓN NACIONAL DE REPARACIÓN Y RECONCILIACIÓN, Disidentes, rearmados y emergentes: ¿bandas criminales o tercera generación?, 2007, en: http://repository.oim.org.co/bitstream/20.500.11788/73/1/COL-OIM\%200190.pdf, [visitado 22.08.2016].

CORTE CONSTITUCIONAL COLOMBIANA, Sentencia C-646, 2001. En: http://www.corteconstitucional.gov.co/relatoria/2001/C-646-01.htm, [visitado 22.08.2016].

CUARTAS, Deiman, Los nuevos estudios sobre las causas de la violencia en Colombia: giro epistemológico e implicaciones políticas e institucionales, 1990-2010. Informe de Investigación, 2015 (inédito).

CUARTAS, Deiman; VALENCIA, Germán, "Exclusión económica y violencia en Colombia, 1990-2008: Una revisión de la literatura", Perfil de Coyuntura Económica $\mathrm{n}^{\mathrm{o}} .14$ (2009), pp. $113-134$. 
Polít. crim. Vol. 12, No 23 (Julio 2017), Art. 8, pp. 267-290.

[http://www.politicacriminal.cl/Vol_12/n_23/Vol12N23A8.pdf]

DE CERTAU, Michel, La invención de lo cotidiano 1, artes de hacer, PESCADOR, Alejandro (Trad.), México: Universidad Iberoamericana, 2007.

DE LA CORTE, Luis, "Apuntes sobre ética y ciencia social: A vueltas con la cuestión del compromiso". Revista de Ciencias Sociales y Humanidades, no 100 (2004), pp. 421459.

DE ZUBIRÍA, Andrés; BECERRA, Gabriel, "Proceso de paz y propuestas de cambio en el sistema político colombiano", Criterio Jurídico Garantista, n 13 (2015), pp. 90-107.

DEAS, Malcolm; GAITÁN, Fernando, Dos ensayos especulativos sobre la violencia en Colombia, Bogotá: FONADE - DNP, 1995.

DUNCAN, Gustavo, "Exclusión, insurrección y crimen”. En: COMISIÓN HISTÓRICA DEL CONFLICTO Y SUS VÍCTIMAS, Contribución al entendimiento del conflicto armado en Colombia. Bogotá, 2015, pp. 249-294.

FALS, Orlando et al., La violencia en Colombia, Vol. I. Bogotá: Santillana, 2010.

FOUCAULT, Michel, Microfísica del poder. Madrid: Ediciones de la Piqueta, 1992.

GARCÍA, Mauricio, "Estado, derecho y crisis en Colombia", Estudios Políticos no 17 (2000), pp. 11-44.

GONZÁLEZ, Julio, “QQué pasa con la pena hoy en día?”, Diálogos de Derecho y Política, Año 3, no 9 (2012), pp. 1-13. Versión online disponible en: http://aprendeenlinea.udea.edu.co/revistas/index.php/derypol/article/viewFile/12318/ 11167 [visitado el 14.07.2016].

GRUPO DE MEMORIA HISTÓRICA, ¡Basta Ya! Colombia: memorias de guerra y dignidad. Informe general del Grupo de Memoria Histórica, Bogotá: Centro Nacional de Memoria Histórica- Departamento para la Prosperidad Social, 2012. En: http://www.centrodememoriahistorica.gov.co/descargas/informes2013/bastaYa/bastaya-colombia-memorias-de-guerra-y-dignidad-2016.pdf, [visitado el 15 de marzo de 2016].

ITURRALDE, Manuel, Castigo, liberalismo autoritario y justicia penal de excepción, Bogotá: Siglo del Hombre Editores- Universidad de los Andes, 2010.

JARAMILLO, Jefferson, "El libro La Violencia en Colombia (1962-1964). Radiografía emblemática de una época tristemente célebre", Revista Colombiana de Sociología, Vol. 35, nº 2 (2012), pp. 35-64.

, "Expertos y comisiones de estudio sobre la violencia en Colombia". Estudios Políticos, no 39 (2011), pp. 231-258.

KLEIN, Naomi, The shock doctrine, en: www.youtube.com. Recuperado el 15 de Marzo de 2013, de The Shock Doctrine: https://www.youtube.com/watch?v=Qm4_vdGkD7o, 2013.

LARRAURI, Elena, "Populismo punitivo...y cómo resistirlo", Jueces para la Democracia, $n^{\circ} 55$ (2006), pp. 15-22.

LEAL, Francisco, "La profesionalización de los estudios políticos en Colombia". Análisis Político, no 3 (1988), pp. 61-80.

LLORENTE, María; GUARÍN, Sergio, "Colombia: éxitos y leyendas de los "modelos" de seguridad ciudadana: Bogotá y Medellín”. En: BASOMBRIO, Carlos (Coord.), ¿A dónde vamos? Análisis de políticas públicas de seguridad en América Latina Washington: Woodrow Wilson International Center for Scholars, 2013, pp.169-202.

MARTÍNEZ, Astrid (Comp.), Violencia y crimen. Ensayos en memoria de Fernando Gaitán Daza, Bogotá: Universidad Externado de Colombia, 2006. 
MUÑOZ, Julián Andrés. "Expertos y política criminal en Colombia".

MONTENEGRO, Armando; POSADA, Carlos, "Criminalidad en Colombia", Coyuntura Económica, $\mathrm{n}^{\circ}$ 1(1995), pp. 81-100.

MUÑOZ, Julián, Saber y poder en la política criminal de la seguridad democrática, 20022006. Medellín: Facultad de Derecho y Ciencias Políticas-Universidad de Antioquia, 2015.

PÉCAUT, Daniel, "Una lucha armada al servicio del statu quo social y político", en: COMISIÓN HISTÓRICA DEL CONFLICTO Y SUS VÍCTIMAS, Contribución al entendimiento del conflicto en Colombia, en: https://www.mesadeconversaciones.com.co/sites/default/files/Informe\%20Comisi_n $\% 20$ Hist_rica\%20de1\%20Conflicto $\% 20 \mathrm{y} \% 20$ sus $\% 20 \mathrm{~V}$ ctimas. $\% 20 \mathrm{La} \% 20$ Habana $\%$ 2C\%20Febrero\%20de\%202015.pdf [visitado el 14.07.2016].

PÉREZ, William, "El estado de excepción es lo de menos". En: MONTOYA Mario; MONTOYA, Nataly (Eds.), Reflexiones constitucionales: a propósito de dos décadas de la Constitución en Colombia, Medellín: Fondo Editorial Eafit, 2012, pp. 203-232.

PÉREZ, William; VANEGAS, Alba; ÁLVAREZ, Carlos, Estado de Derecho y sistema penal. Medellín: Biblioteca Jurídica Diké-Universidad de Antioquia, 1997.

RUBIO, Mauricio, Crimen e impunidad. Precisiones sobre la violencia, Bogotá: CEDE (Uniandes) - Tercer Mundo, 1999.

SÁNCHEZ, Gonzalo, Colombia: violencia y democracia, Medellín: La Carreta editoresIEPRI, 2009.

SÁNCHEZ, Gonzalo; PEÑARANDA, Ricardo, Pasado y presente de la violencia en Colombia, Bogotá: CEREC, 1986.

SANDOVAL, Emiro, Sistema penal y criminología crítica, Bogotá: Temis, 1985.

SOTOMAYOR, Juan, "Las recientes reformas penales en Colombia: un ejemplo de irracionalidad legislativa", Nuevo Foro Penal, no 71 (2007), pp. 13-66.

SWEDBERT, Richard, The art of social theory, Princeton: Princeton University Press, 2014.

TIMMERMANS, Stefan; TAVORY, Iddo, "Theory construction in qualitative research: from grounded theory to abductive analysis", Sociological Theory, no 30 (2002), pp. 167-186.

URIBE, María Teresa, "Las soberanías en vilo en un contexto de guerra y paz", Estudios Políticos $\mathrm{n}^{\circ}$ 13(1998), pp. 11-37.

URIBE, Mauricio, La nación vetada: Estado, desarrollo y guerra civil en Colombia. Bogotá: Universidad Externado de Colombia, 2013.

URREGO, Miguel, Intelectuales, Estado y Nación en Colombia: de la guerra de los mil días a la Constitución de 1991, Bogotá: Siglo del Hombre, 2002.

WAQUANT, Löic, Las cárceles de la miseria, PONS, Horacio (Trad.), Buenos Aires: Manantial, 2004.

WILSON, James; KELLING, George, "Ventanas rotas: la policía y la seguridad en los barrios”, FRIDMAN, Daniel (Trad.), Delito y sociedad. Revista de ciencias sociales, n $15-16$ (2001), pp. 67-79.

ZALAMEA, Alberto, Las jornadas de mayo, Bogotá: Antares, 1957.

Experto 1, entrevistado el 10 de abril de 2015.

Experto 2, entrevistado el 14 de abril de 2015.

Experto 3, entrevistado el 16 de abril de 2015.

Experto 4, entrevistado el 14 de abril de 2016.

Experto 5, entrevistado el 15 de abril de 2016. 